\title{
Theoretically studying the optoelectronic properties of oligomers based on 2.7-divinyl-cabazole
}

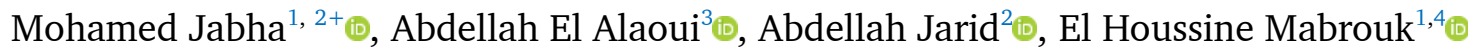

1. University of Moulay Ismail, Faculty of Sciences and Technics, Errachidia, Morocco.

2. University of Cadi Ayyad, Faculty of Sciences Semlalia, Marrakech, Morocco.

3. University of Moulay Ismail, Faculty of Sciences, Meknes, Morocco.

4. Sidi Mohamed Ben Abdellah University, Faculty of Sciences, Fez, Morocco.

+Corresponding author: Mohamed Jabha, Phone: +212614018410, Email address: m.jabha@edu.umi.ac.ma

\section{ARTICLE INFO}

Article history:

Received: December 13, 2020

Accepted: October 19, 2021

Published: January 01, 2022

Section Editor: Assis Vicente Benedetti
Keywords
1. optoelectronic
2. 2.7-divinylcabazole
3. photovoltaic
4. organic
5. DFT
6. B3LYP

ABSTRACT: This work consists of theoretically studying the electronic and optical properties of 9(4-octyloxyphenyl)-2.7-divinyl-carbazole (PCrV) oligomers. This study has been undertaken using the density functional theory (DFT) method at the B3LYP/6-31G (d,p) level and BP86/6-31G (d,p) level of theory. To evaluate the PCrV-basis systems properties, the structural optimization without geometrical restrictions was performed on the total potential energy surface (TPES). In order to ensure good absorption of radiation, the interest was in increasing the efficiency of the organic photovoltaic cell. For this effect, the (HOMOLUMO) gap energy of such compounds was reduced in terms of geometric and electronic structure. The BP86 functional gives good results at the energy gap level, while other parameters using the B3LYP functional give the best results.

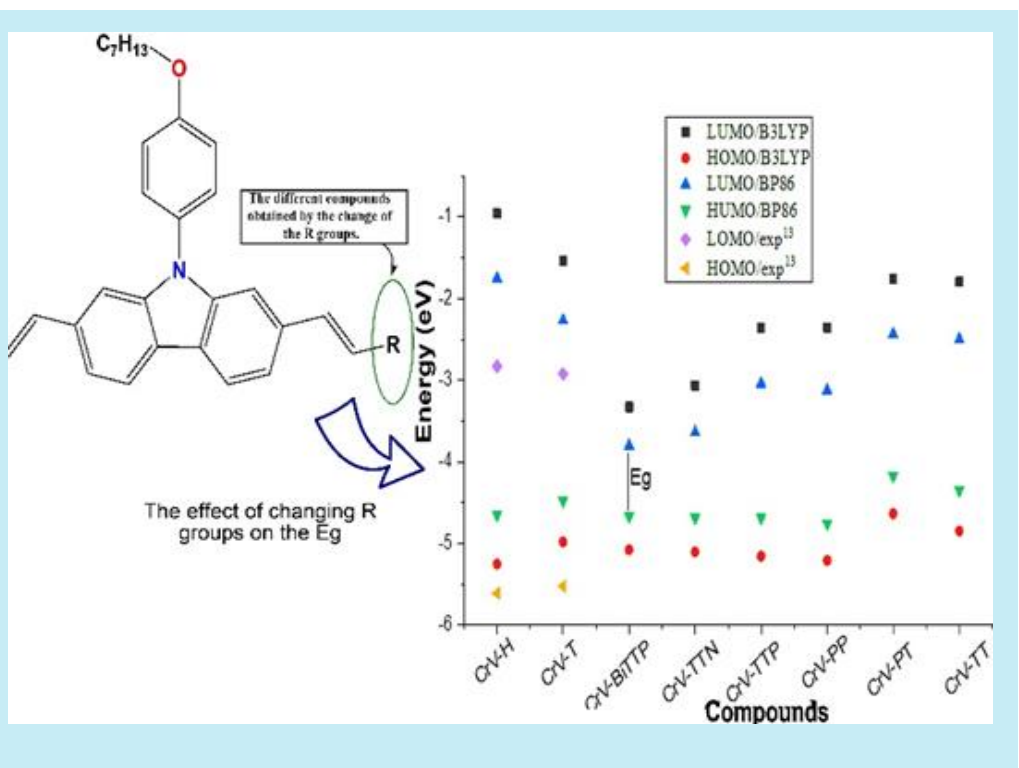




\section{Introduction}

The growing energy needs of daily lives on the one hand, and the strong growth of the world population on the other are leading to a search for new sources of energy (hydroelectricity, wind, sun), as well as the mastery of materials with new properties (semiconductors, aluminum, composites, rare earths, etc...). In addition to the speed of technological development, especially plastic-based technology, and the development of computational performance, facilitates he realization of new organic materials, the discovery and improvement of new properties of semiconductor organic materials, and the expansion of the field of use, especially in the field of photovoltaic (Baek et al., 2012; Bourass et al., 2017; Toub, 2007).

Polymeric (Fukuta et al., 2015; Huang, 2015; Scharber and Sariciftci, 2013) (organic) solar cells are becoming more and more important in the field of scientific research. These cells have many potential advantages over inorganic solar cells (Koh et al., 2008; Tarascon, 2011; Zeyada et al., 2016), such as relatively low cost, lightweight, interesting electronic properties, good mechanical properties and ease of processing. However, the main limitations of this type are the low power-to-energy conversion efficiency and the relative instability compared to silicon-based solar cells. However, this efficiency depends on highest occupied molecular orbital (HOMO), lowest unoccupied molecular orbital (LUMO), and energy gap properties.

Derivatives of 2.7-carbazole (Blouin et al., 2008; Chen et al., 2014; Zhao et al., 2010) are organic materials (these oligomers) possessing the properties of a semiconductor, known by their high stability due to the presence of nitrogen atoms, by their wide range of industrial applications thanks to their important physicochemical property. The addition of alkyl chains on the nitrogen atom increases the solubility, which facilitates the synthesis of these oligomers.

The interest is in increasing the efficiency of the organic photovoltaic cell, seeking to decrease the gap energy (HOMO-LUMO), to characterize these compounds in terms of geometrical and electronic structures to ensure a good absorption of radiation.

This work consists in theoretically studying the electronic and optical properties of oligomers based on 9-(4-octyloxyphenyl)-2.7-divinylcabazole $\quad(\mathrm{PCrV})$ (Fig. 1) using the density functional theory (DFT) method under two different functionals with the same base $(6-31 \mathrm{G}[\mathrm{d}, \mathrm{p}])$. The optical properties are obtained by the time-dependent density functional theory (TDDFT) method, in order to show the reliability of one of these functionals, and their fairness with the experimental results (Leclerc et al., 2006).

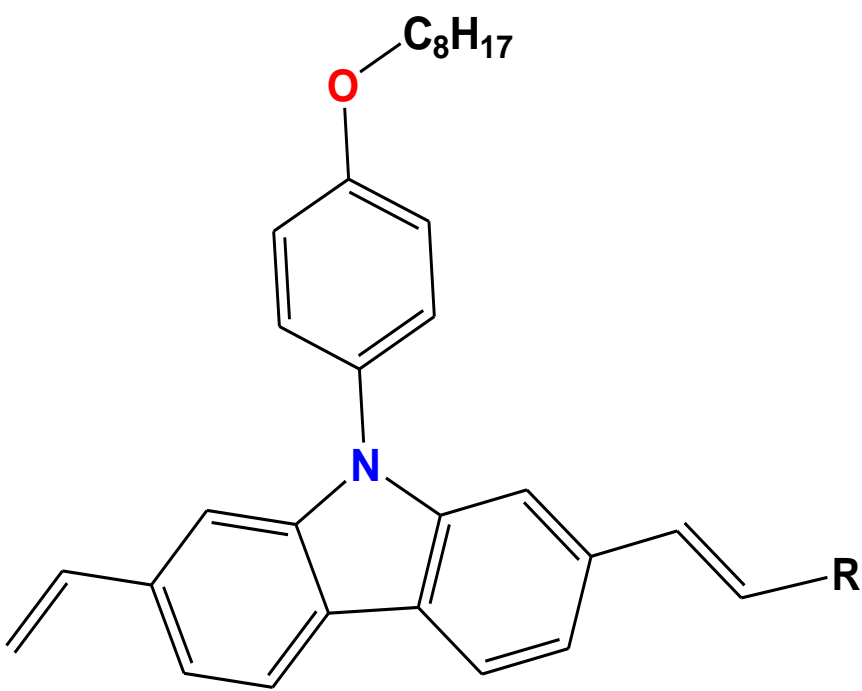

Figure 1. 9-(4-octyloxyphenyl)-2.7-divinylcabazole.

The calculated band gap energy of these oligomers is between $0.87 \mathrm{eV}$ and $2.9 \mathrm{eV}$ at the BP86/6-31G $(\mathrm{d}, \mathrm{p})$ base of the DFT method, while at the B3LYP/6-31G $(d, p)$ base of the same method the gap energy is between $1.75 \mathrm{eV}$ and $3.86 \mathrm{eV}$. However, the experimental gap energy is $2.8 \mathrm{eV}$. Absorption properties, optical properties and electron density are also studied.

\subsection{The studied systems}

The basic molecule 9-(4-octyloxyphenyl)-2.7divinylcabazole was chosen, to which was linked a radical $\mathrm{R}$, which was changed to obtain the different systems studied. The different $\mathrm{R}$ groups were introduced to study their effects on the electronic structure and on the optoelectronic properties. Below are the structures of the $\mathrm{R}$ groups and the abbreviation of different oligomers (Fig. 2). 


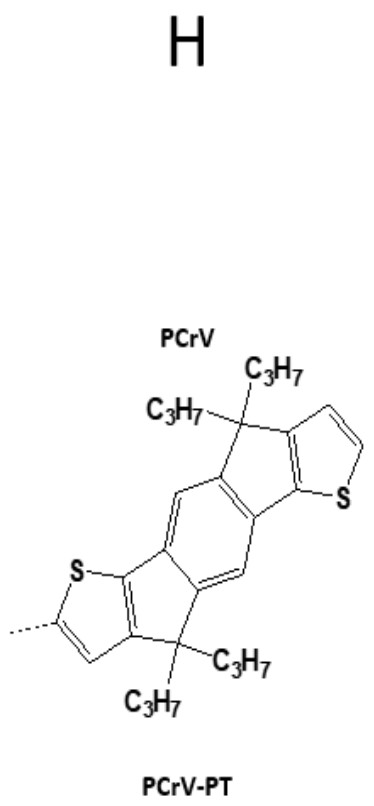

Figure 2. Structures and symbol of the R groups.

\section{Methodology and computational details}

Theoretical calculations of all oligomers were performed without constraint, using the Gaussian 09 software (Gaussian, 2009). The geometrical study of neutral systems in its fundamental state, optimization and frequency was evaluated using the functional density theory (DFT) (Baseden and Tye, 2014; Ganji et al., 2016; Garrity et al., 2014), under the B3LYP functional (Becke, three-parameter, Lee-Yang-Parr) (Becke, 1988; Gill et al., 1992; Xu and Goddard, 2004) and the Becke Perdew hybrid (BP86) (Cai et al., 2002; Cramer and Truhlar, 2009) functional with the base 6.31G (d, p) (Francl et al., 1982; Mitin et al., 2003; Nishiyama et al., 1975) for all atoms.

The geometrical structures of the neutral molecules were optimized without constraints, the convergence of all calculations was confirmed by the absence of negative frequencies.

The energy levels HOMO, LUMO (gap energy) are calculated from the optimized structures. Photovoltaic parameters are obtained from the optimized geometries. In order to calculate the optical properties by the TDDFT method (Boussaidi et al., 2016; Jacquemin et al., 2009; Laurent and Jacquemin, 2013), with the two functionals (B3LYP and BP86) at the atomic base $6-31 \mathrm{G}(\mathrm{d}, \mathrm{p})$ from the optimized structures under the same functionals.
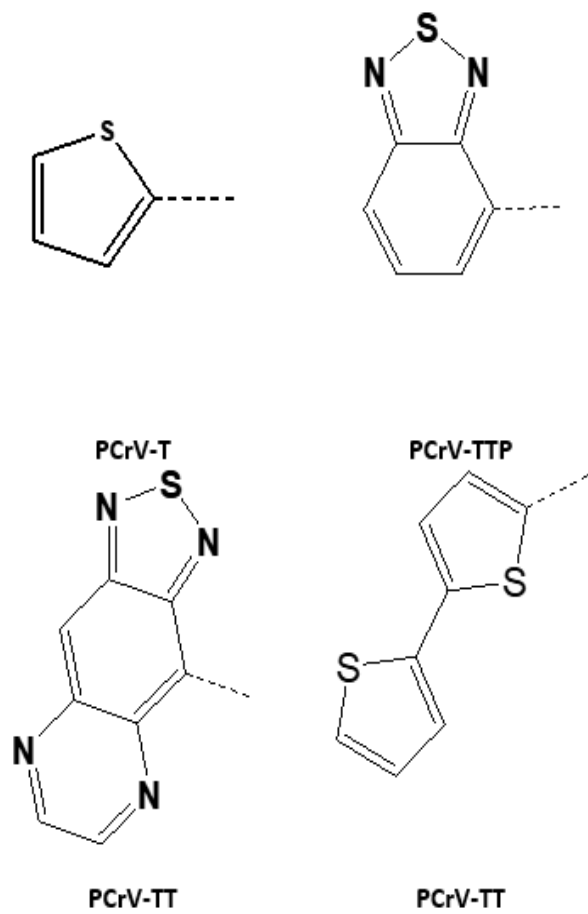

\section{Results and discussion}

\subsection{Geometrical study}

The geometrical study of the oligomers carried out at the level of the functionals B3LYP and BP86 of the DFT method under the atomic base 6-31G $(d, p)$. The grafting of the R groups increasing the number of atoms of each oligomer causes the total energy of each system to decrease, i.e., the oligomers stabilize more and more. Table 1 and Fig. 3 describe the structural parameters with the two functionals. Nomenclature, abbreviations, and symbols should follow International Union of Pure Applied Chemistry (IUPAC) recommendations.

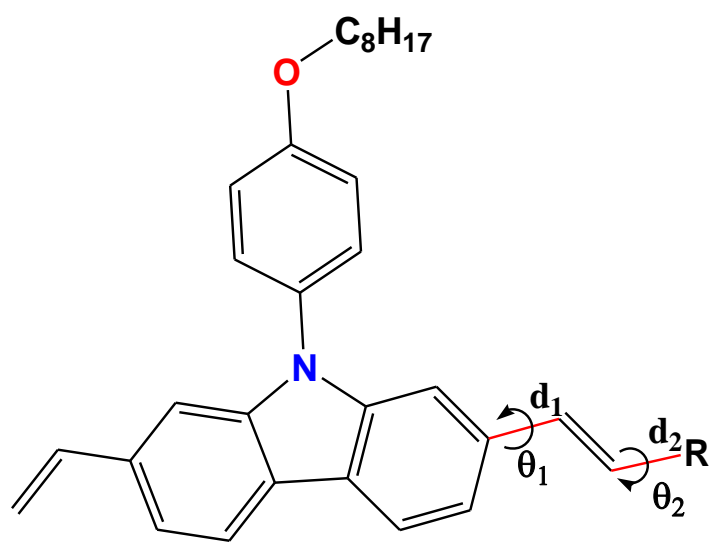

Figure 3. Dihedral angles and distances in the studied oligomers. 
Note that the distances $\mathrm{d}_{1}$ and $\mathrm{d}_{2}$ represent, respectively, the charge transfer bridge between the donor part (D) and the spacer (vinyl) with the groups R, and $\mathrm{q}_{1}$ and $\mathrm{q}_{2}$ are the dihedral angles between the donor (D) and the spacer on the one hand and the groups $\mathrm{R}$ and the spacer on the other hand (Fig. 3). The values obtained from the optimization are grouped in Tab. 1.

Table 1. Calculated values of $d_{1}$ and $d_{2}$ bond lengths (̊) at a B3LYP/6-31G (d,p) levels and BVP86/6-31G $(\mathrm{d}, \mathrm{p})$ levels.

\begin{tabular}{|c|c|c|c|c|}
\hline Compound & $d_{1} / \mathbf{B} 3 L Y P$ & $d_{1} /$ BP86 & d2/B3LYP & $\mathrm{d}_{2} / \mathbf{B P 8 6}$ \\
\hline PCrV & 1.4708 & 1.47077 & 1.08490 & 1.09265 \\
\hline PCrV-T & 1.46102 & 1.45936 & 145015 & 1.44789 \\
\hline $\begin{array}{l}\text { PCV- } \\
\text { BiTTP }\end{array}$ & 1.45462 & 1.45295 & 1.43948 & 1.43839 \\
\hline PCrV-TTN & 1.45787 & 1.45577 & 1.44906 & 1.44645 \\
\hline PCrV-TTP & 1.46087 & 1.45906 & 1.45838 & 1.45642 \\
\hline PCrV-PP & 1.46166 & 1.45959 & 1.45938 & 1.45689 \\
\hline & & & & \\
\hline PCrV-TT & 1.45954 & 1.45736 & 1.44148 & 1.43837 \\
\hline
\end{tabular}

According to Tab. 1, it is possible to observe that the values of the bonds obtained from the calculations do not undergo a great change, generally the lengths are close to that of carbon-carbon $(1.48 \AA)$. In resonance, especially the values obtained by the B3LYP functional, the $\mathrm{d} 2$ bond (Fig. 3) of the PCrV oligomer is a $\mathrm{C}-\mathrm{H}$ single bond, and the closest value to the experimental one is that obtained by the B3LYP functional.

The introduction of the vinylene bond in the $\pi$ conjugate system (Kim et al., 2016; Nazim et al., 2015) is an efficient strategy to modulate the electronic properties of the systems to lower the gap energy. It is also a good method to obtain coplanar molecules due to the relatively small dihedral angle between the vinyl group and the grafted $\mathrm{R}$ groups (Fig. 2).

The increase in the value of the dihedral angle contributes to the loss of coplanarity between donor and acceptor. In order to exploit these geometrical and structural parameters of the studied molecules internucleus distances (di) and dihedral angles ( $\theta \mathrm{i})$, the most stable conformations are obtained after optimization in their fundamental state using the DFT method. The results obtained are illustrated in Fig. 4a.
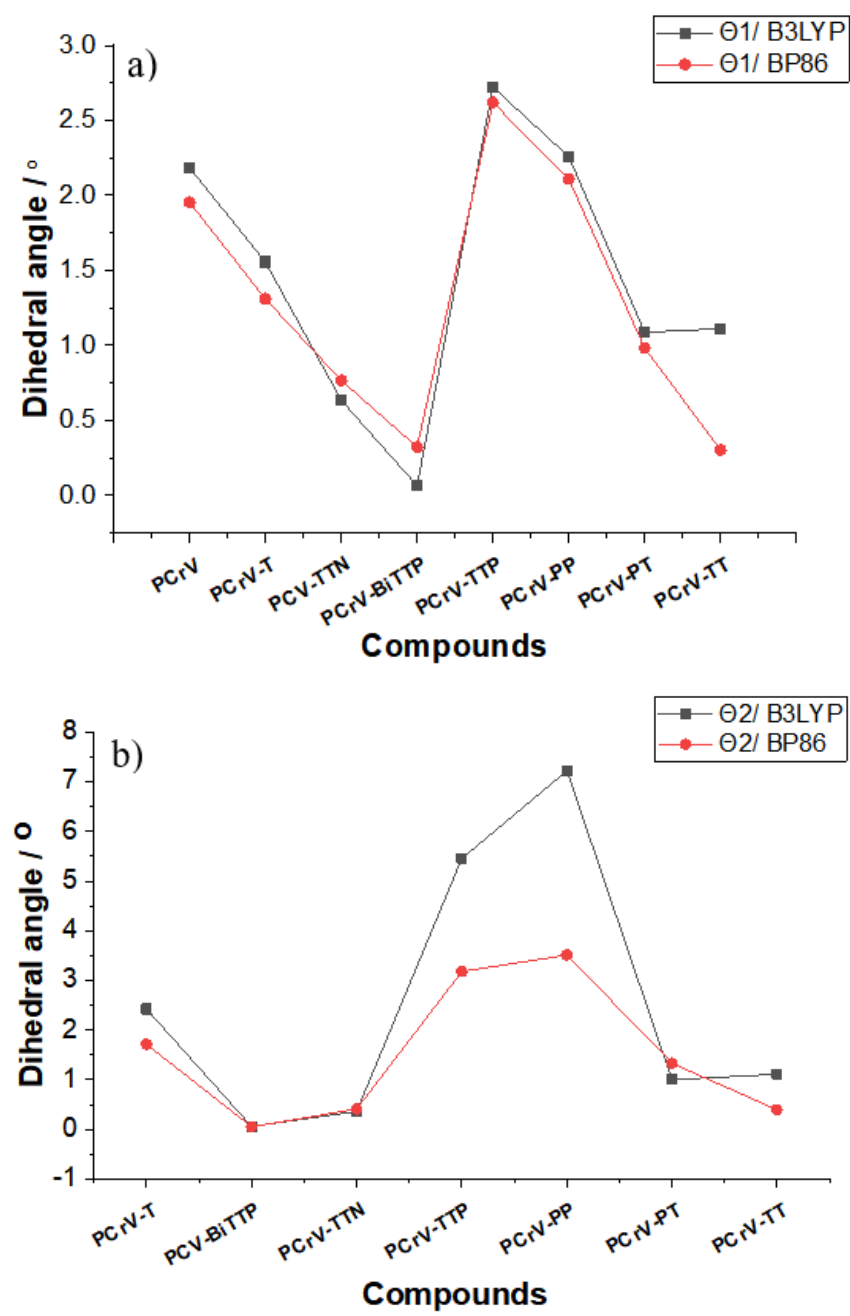

Figure 4. $\theta_{1}$ (a) and $\theta_{2}(\mathbf{b})$ dihedral angles $\left(^{\circ}\right)$ obtained by B3LYP/6-31G (d, p) levels and BP86/6-31G (d, p) levels.

It is noticed that the dihedral angle $\theta_{\mathrm{i}}$ between the electron donor groups and the spacer for all compounds varies between 0.5 and $2.75^{\circ}$. Regardless of the study functional (B3LYP and BP86) except the dihedral angle of the PCrV-BiTTP oligomer for both functionals $\left(0.01^{\circ}\right.$ for the B3LYP functional and $0.35^{\circ}$ for the BP86 functional), i.e., the PCrV-BiTTP oligomer is almost coplanar, when the geometries are optimized by the B3LYP functional. On the other hand, for both functionals (B3LYP and BP86) the values of the dihedral angle $\mathrm{q}_{2}$ between the spacer and the $\mathrm{R}$ groups for the PCrV-BiTTP oligomer is $0.02^{\circ}$ for B3LYP and 0.03 for BP86. The values of the other oligomers show that the compounds studied have a noncoplanar structure especially for compounds having the PP, TTP, 
PT groups, this is probably due to the steric effect of the $\mathrm{R}$ groups.

\subsection{Optimized structures}

The optimized molecular structures are shown in Fig. 5. The structures have been optimized in its neutral state by the DFT method under the base 6-31g (d,p) with the functionals B3LYP and BP86 in order to obtain the optoelectronic and photovoltaic properties.

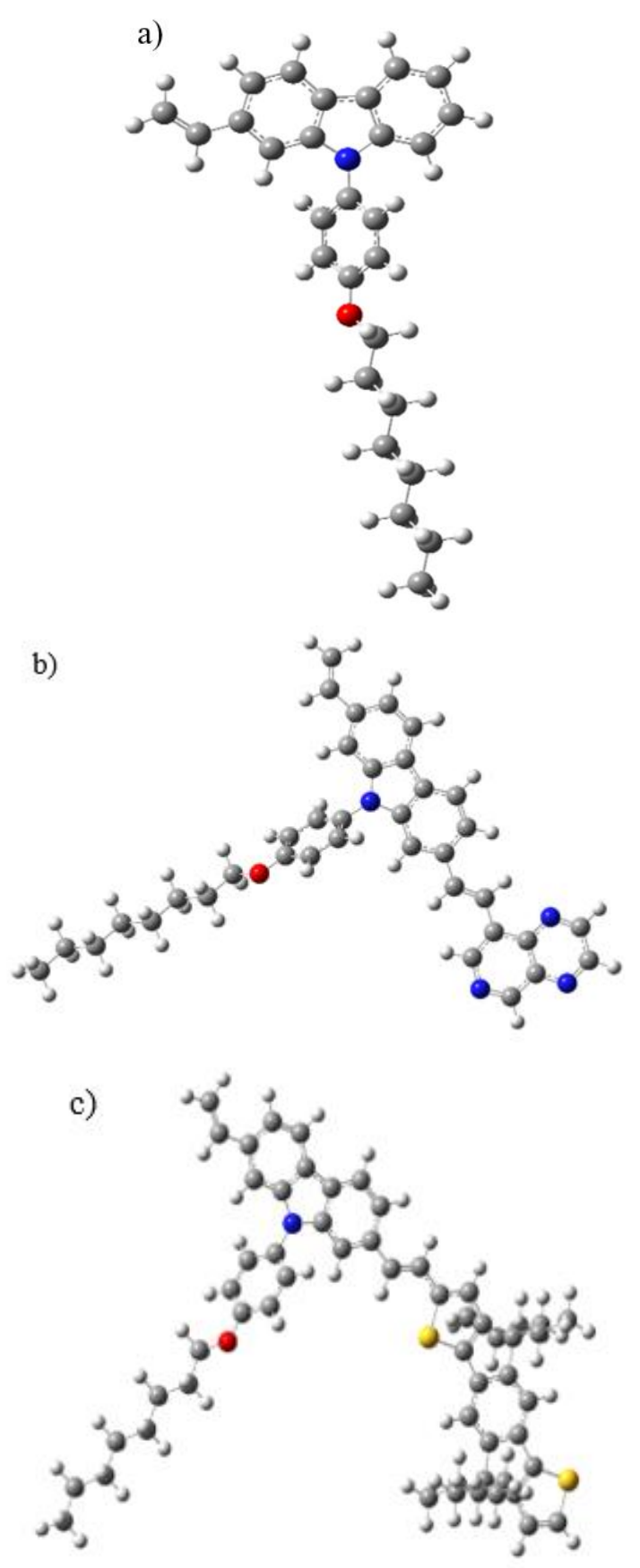

d)
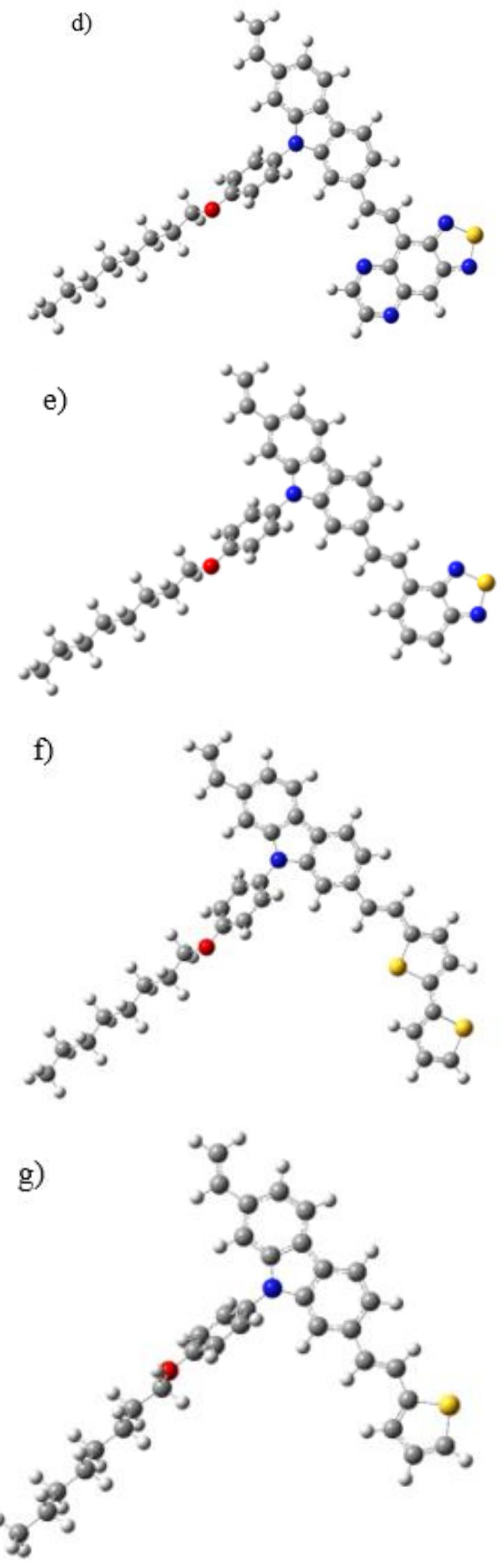


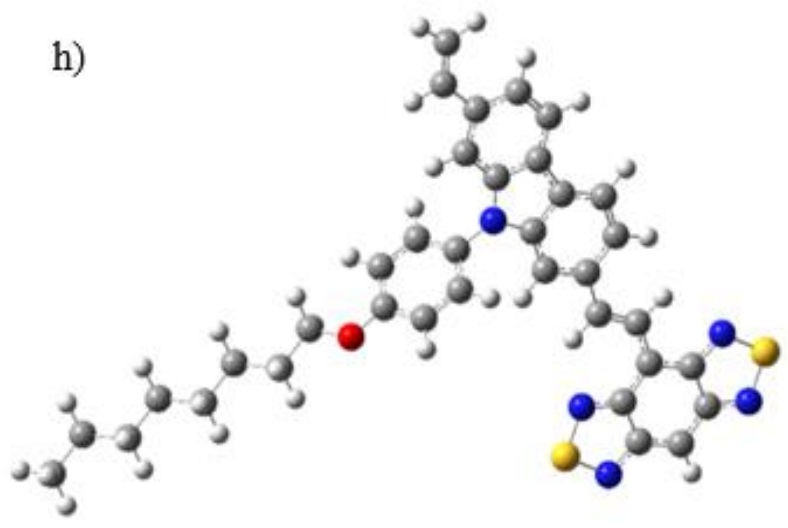

Figure 5. The most stable conformations of oligomers optimized by the DFT method. (a) PCrV; (b) PCrV-PP; (c) PCrV-PT; (d) PCrV-TTN; (e) PCrV-TTP; (f) PCrVTT; (g) PCrV-T; (h) PCrV-BiTTP.

\subsection{Electronic properties}

The theoretical knowledge of the HOMO and LUMO energy levels of the components is fundamental for the study of organic solar cells. Electronic properties are of paramount importance for the study of this type of molecules. Among these properties, it is mentioned the LUMO, HOMO levels, and the energy gap (Davidson et al., 1984; Jabha and Abdellah, 2018; Kato et al., 2014; 2015), the latter being one of the most important factors in the control of physical and photovoltaic properties. The theoretical and experimental gap energy values of the $\mathrm{PCrV}$ and $\mathrm{PCrV}$ $\mathrm{T}$ oligomers were compared, which are, respectively, 2.78 and $2.6 \mathrm{eV}$ (Leclerc et al., 2006) (Fig. 6).

The values plotted in the graph shown in Fig. 6 demonstrate that the energy gap decreases when the $\mathrm{R}$ groupings, $\mathrm{R} \neq \mathrm{H}$, on the carbon skeleton are added. This phenomenon is apparent specifically for $\mathrm{R}=$ BiTTP and $\mathrm{R}=$ TTN.

One of the most important parameters for determining the quality of $\pi$-conjugate compounds is the value of the gap. More than the energy gap close to that of a semiconductor, the more the compose quality is candidate for use in the manufacture of electronic devices. For this reason, the most efficient strategy to have good molecules is to increase the aromaticity of these compounds by introducing $\mathrm{R}$ groups. All the calculations made by DTF under the functional B3LYP with the atomic base $6-31 \mathrm{G}(\mathrm{d}, \mathrm{p})$, show a decrease of the energy gap of the oligomers, but for the oligomers $\mathrm{PCrV}$ and PCrV-T a band gap far from the experimental one of these molecules is obtained. On the other hand, the calculations made by the BP86 functional of the DFT method under the atomic base 6-31G (d,p) show a proximity of the calculated gap energy and the experimental band gap, as well as the decrease of the gap energy Eg of the oligomers.

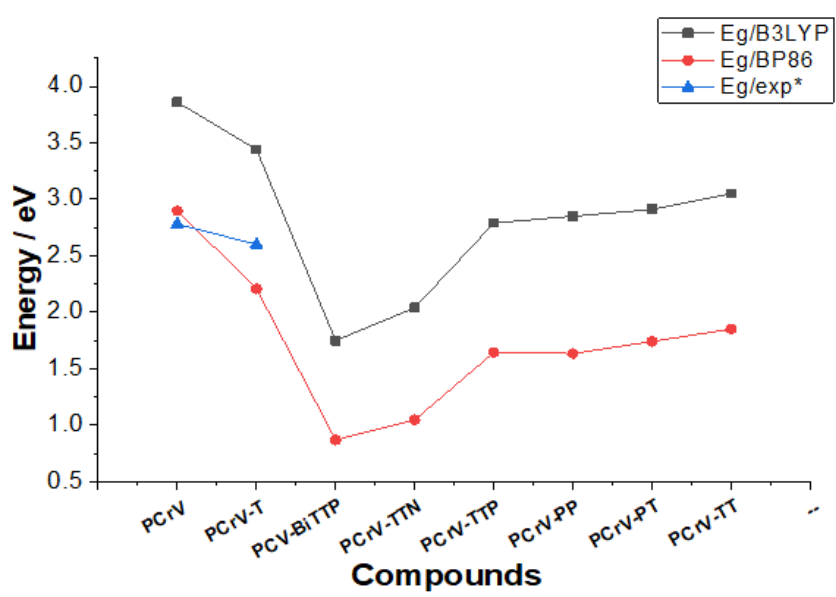

Figure 6. Data of band gap energy of all compounds obtained by B3LYP and BP86 functional.

Figure 7 shows that the band gap is generally low for all systems studied, the observed decrease in the band is due to the addition of the conjugated $\mathrm{R}$ group.

These results are confirmed by the propagation of the electron density. This phenomenon appears very clearly below (see Fig. 11). The electron density of LUMO is higher around the $\mathrm{R}$ unit for systems with smaller energy gap and precisely for the oligomers PCrV-BiTTP, PCrV-TTN, PCrV-TTP. This feature precisely allows these systems (PCrV-BiTTP, PCrVTTN, PCrV-TTP) to be used to produce and manufacture electronic devices for photovoltaics. 


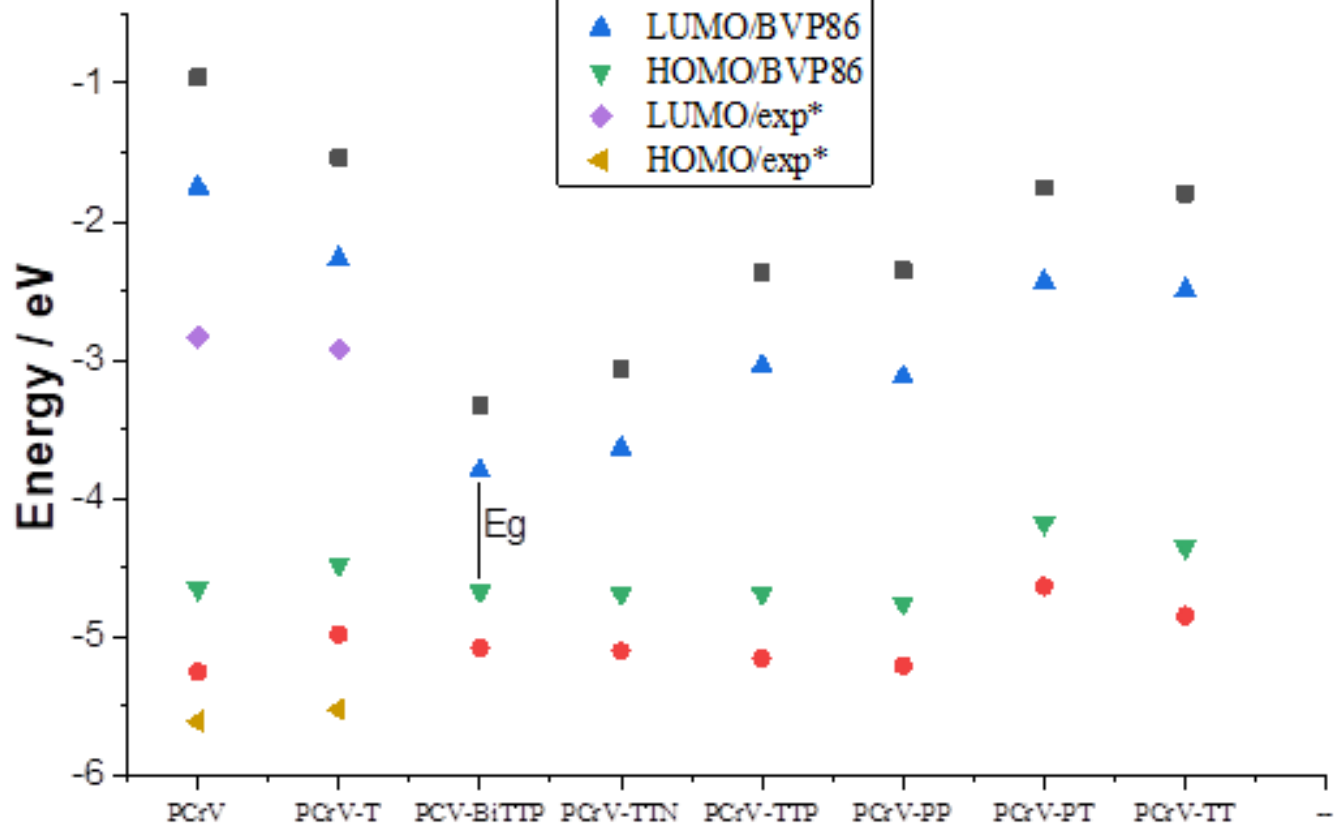

\section{Oligomers}

Figure 7. Data of absolute energy of the frontier orbital HOMO and LUMO for all compounds: obtained at DFTB3LYP and DFT-BP86 methods.

\subsection{Electrochemical properties}

According to the optimization of structures by the DFT method with the atomic base 6-31G $(\mathrm{d}, \mathrm{p})$ and at the functional levels B3LYP and BP86, several chemical parameters were determined, namely: the electronic chemical potential $\mu$, the electronegativity and the global hardness (Ayers, 2007; Cherkasov et al., 1998; Miranda-Quintana et al., 2016; Zhou and Parr, 1989).

The electronegativity (Eq. 1) is opposite of the chemical electronic potential $\mu$ (Eq. 2), the latter and the global hardness (Eq. 3) are calculated from the energies of the molecular orbital boundaries according to the following relationships (Khalid et al., 2020; Parr and Pearson, 1983; Zhou and Parr, 1989):

$\mu=-\chi$

$\mu=\frac{E_{H O M O}+E_{L U M O}}{2}$

$\eta=\frac{E_{L U M O}-E_{H O M O}}{2}$

In Tabs. 2 and 3, the electronic and chemical parameters obtained from the optimized structures are presented, namely: HOMO and LUMO energies, chemical potential, overall hardness and electronegativity of the compounds (PCrV-R) and the Bis-PCBM acceptor. From these results (Tabs. 2 and 3), it can be seen that the Bis-PCBM compound has the lowest chemical potential value $(-4.95 \mathrm{eV})$ compared to the other compounds.

Table 2. HOMO (eV) and LUMO (eV) energies, chemical potential $(\mathrm{eV})$, overall hardness $(\mathrm{eV})$ and electronegativity (eV) obtained by B3LYP/6-31G (d.p).

\begin{tabular}{|l|c|c|c|c|c|} 
Compounds & $\begin{array}{c}\text { LUMO } \\
(\mathbf{e V})\end{array}$ & $\begin{array}{c}\text { HOMO } \\
(\mathbf{e V})\end{array}$ & $\begin{array}{c}\mu \\
(\mathbf{e V})\end{array}$ & $\begin{array}{c}\eta \\
(\mathbf{e V})\end{array}$ & $\begin{array}{c}\chi \\
(\mathbf{e V})\end{array}$ \\
\hline PCrV & -1.38 & -5.24 & -3.31 & 1.93 & 3.31 \\
\hline PCrV-T & -1.54 & -4.98 & -3.26 & 1.72 & 3.26 \\
\hline PCV-BiTTP & -3.33 & -5.08 & -4.20 & 0.87 & 4.20 \\
\hline PCrV-TTN & -3.06 & -5.10 & -4.08 & 1.02 & 4.08 \\
\hline PCrV-TTP & -2.36 & -5.15 & -3.76 & 1.40 & 3.76 \\
\hline PCrV-PP & -2.35 & -5.21 & -3.78 & 1.43 & 3.78 \\
\hline PCrV-PT & -1.75 & -4.63 & -3.19 & 1.44 & 3.19 \\
\hline PCrV-TT & -1.79 & -4.85 & -3.32 & 1.53 & 3.32 \\
\hline Bis-PCBM & -3.80 & -6.10 & -4.95 & 3.50 & 4.95 \\
\hline
\end{tabular}


Table 3. HOMO $(\mathrm{eV})$ and LUMO $(\mathrm{eV})$ energies, chemical potential $(\mathrm{eV})$, overall hardness $(\mathrm{eV})$ and electronegativity (eV) obtained by BP86/6-31G (d.p).

\begin{tabular}{|c|c|c|c|c|c|}
\hline Compounds & $\begin{array}{c}\text { LUMO } \\
(\mathrm{eV})\end{array}$ & $\begin{array}{l}\text { HOMO } \\
(\mathrm{eV})\end{array}$ & $\begin{array}{c}\mu \\
(\mathrm{eV})\end{array}$ & $\begin{array}{c}\eta \\
(\mathrm{eV})\end{array}$ & $\begin{array}{c}\chi \\
(\mathrm{eV})\end{array}$ \\
\hline PCrV & -1.75 & -4.65 & -3.20 & 1.45 & 3.20 \\
\hline PCrV-T & -2.27 & -4.47 & -3.37 & 1.10 & 3.37 \\
\hline PCV-BiTTP & -3.80 & -4.67 & -4.23 & 0.43 & 4.23 \\
\hline PCrV-TTN & -3.64 & -4.69 & -4.16 & 0.52 & 4.16 \\
\hline PCrV-TTP & -3.04 & -4.69 & -3.86 & 0.82 & 3.86 \\
\hline PCrV-PP & -3.12 & -4.76 & -3.94 & 0.82 & 3.94 \\
\hline PCrV-PT & -2.43 & -4.17 & -3.30 & 0.87 & 3.30 \\
\hline PCrV-TT & -2.50 & -4.35 & -3.42 & 0.93 & 3.42 \\
\hline Bis-PCBM & -3.80 & -6.10 & -4.95 & 3.50 & 4.95 \\
\hline
\end{tabular}

\subsection{Chemical potential}

Figure 8 shows that all systems studied have a donor character with a small difference in the ability to release electrons easily. The passage of electrons will take place from the compounds with the highest chemical potential to the one with the lowest chemical potential, therefore, since the value of the chemical potential of Bis-PCBM is smaller in comparison to the other compounds, it can be deduced that Bis-PCBM will behave as an electron acceptor while the others will behave as electron donors.

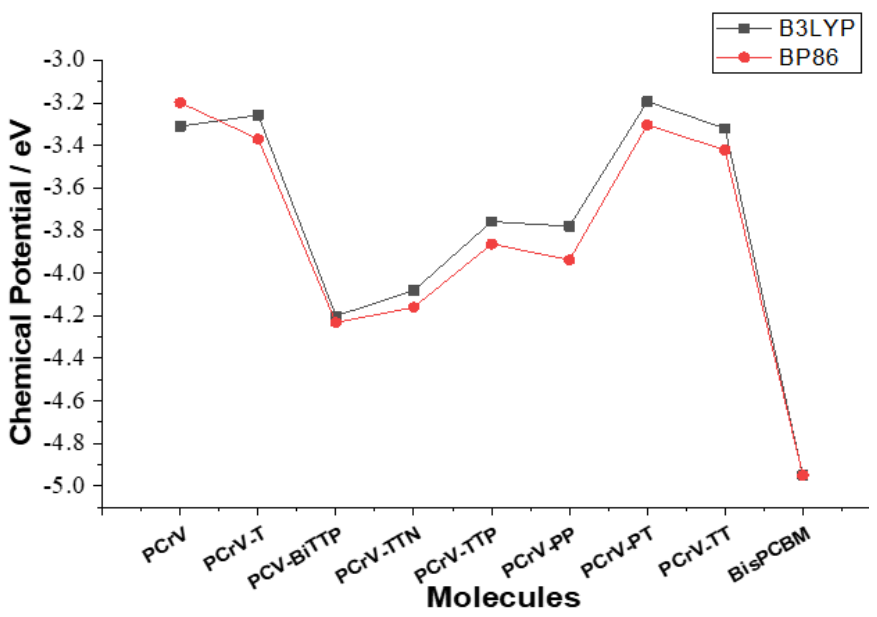

Figure 8. Chemical potential of oligomers studied by the DFT method under the base 6-31G (d,p).

\subsection{Electronegativity of the different compounds}

Comparing the different values of electronegativity shown in Fig. 9, it can be noticed that Bis-PCBM is the molecule with the highest value of electronegativity (Tabs. 2 and 3). Therefore, the molecule with the highest electronegativity value is likely to attract electrons strongly. Here, Bis-PCBM is the electron accepting molecule.

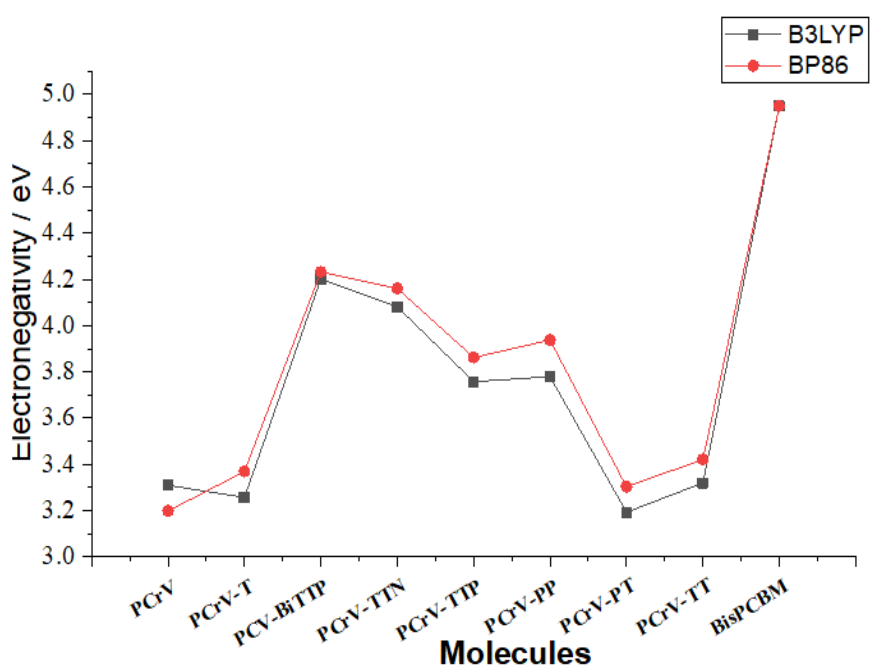

Figure 9. Electronegativities of oligomers obtained by DFT/6-31G (d,p).

\subsection{Global hardness of different molecules}

According to Fig. 10, the oligomer with the highest global hardness ( $\mathrm{PCrV}$ and PCrV-T). These molecules hardly undergo any rearrangement of their electronic structure and will have the lowest reactivity.

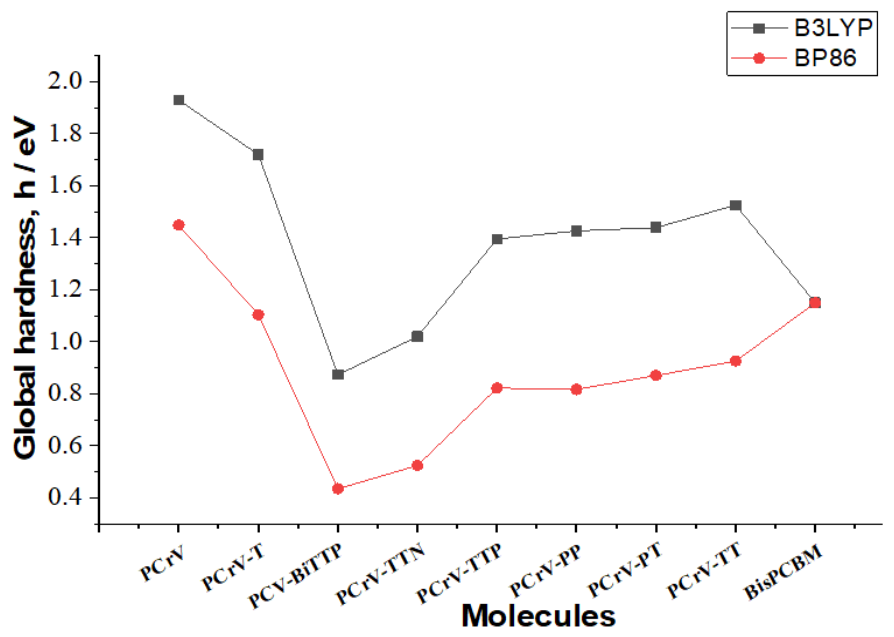

Figure 10. The global hardness obtained by DFT/6-31G $(\mathrm{d}, \mathrm{p})$. 
The oligomer PCrV-BiTTP can easily undergo a change of their electronic structure by chemical reaction, probably leading to the creation of covalent bonds, so it is easier to polymerize this molecule.

\subsection{The frontier orbitals}

Figure 11 presents the electron density of the HOMO and LUMO orbitals of the studied oligomers. These give a qualitative and rational indication of the electronic properties of the studied oligomers.

\section{LUMO}
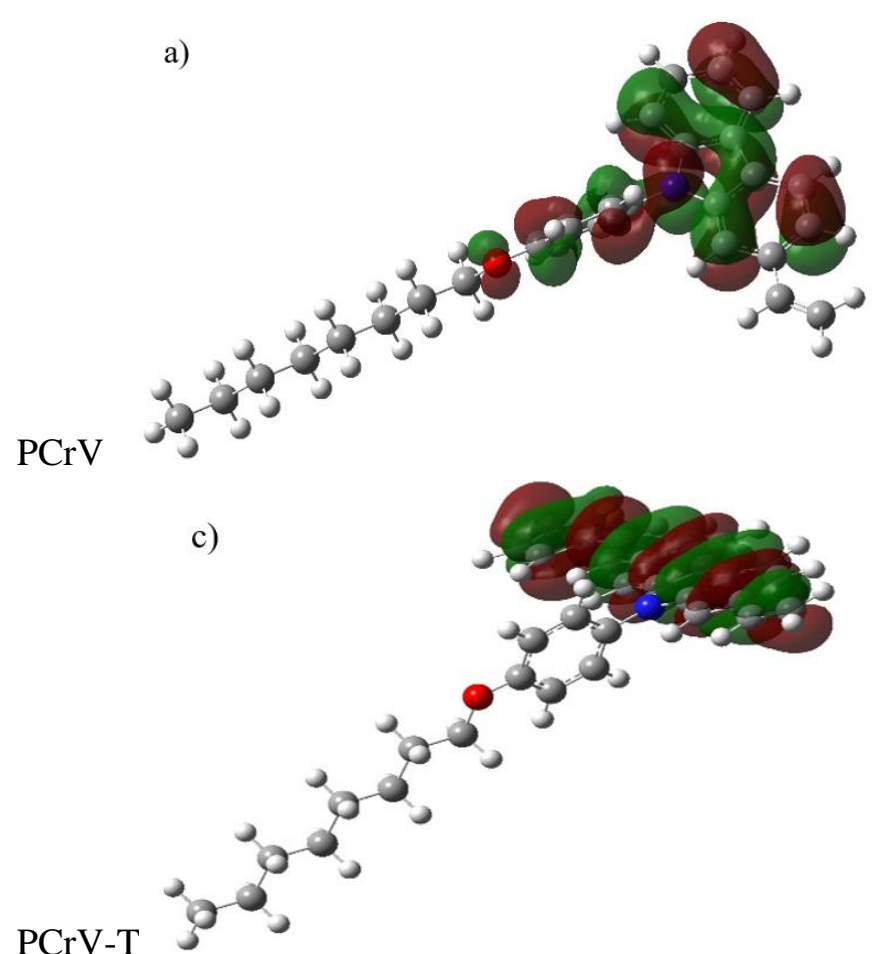

PCV-BiTTP
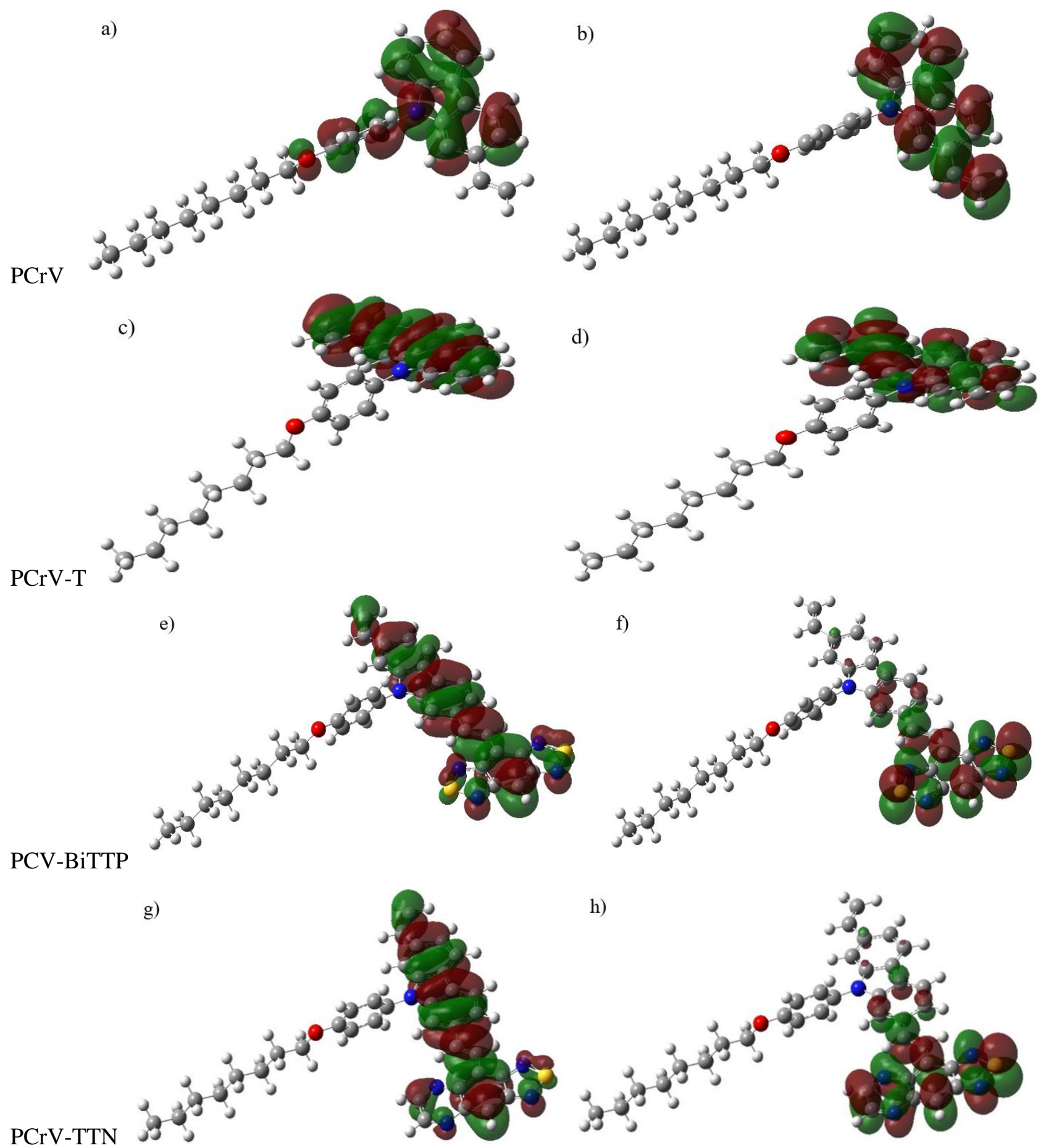

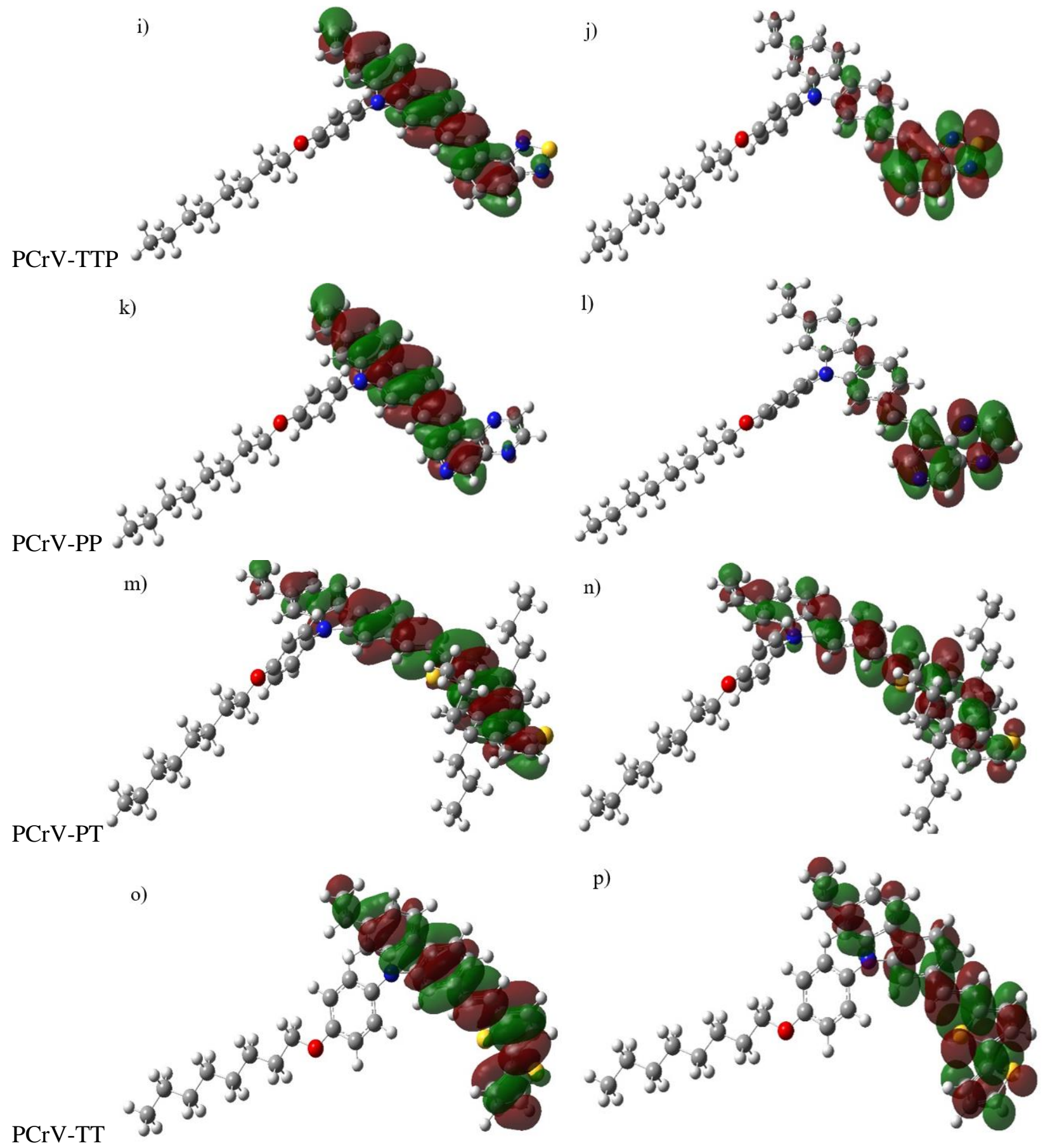

Figure 11. The contour plots of HOMO $(\mathbf{a}, \mathbf{c}, \mathbf{e}, \mathbf{g}, \mathbf{i}, \mathbf{k}, \mathbf{m}, \mathbf{o})$ and $\operatorname{LUMO}(\mathbf{b}, \mathbf{d}, \mathbf{f}, \mathbf{h}, \mathbf{j}, \mathbf{l}, \mathbf{n}, \mathbf{p})$ orbitals of the studied compounds.

Figure 11 shows that the electron density is spread over the entire carbon skeleton at the HOMO level, and an almost complete shift towards the $\mathrm{R}$ group at the LUMO level. Also note the absence of electron density on the carbon chain bound to the nitrogen $(\mathrm{N})$ in carbazole. Thus, this chain has no optical effect. Its main role is the solubilization and stability of the system. 


\subsection{Optical proprieties}

Table 4 shows the values of the excitation energy $E_{\text {ex }}$ $(\mathrm{eV})$, the absorption maximum (Jabha and Abdellah, 2018; Leliège et al., 2013) $\lambda_{\max }(\mathrm{nm})$ and the oscillator strength $\left(\mathrm{F}_{\mathrm{os}}\right)$ for all the molecules studied. These calculated values are obtained by the methods TDB3LYP/6-31G(d,p) and TD-BP86/6-31G(d,p).

Table 4. Electronic transition data obtained by the TD/DFT-B3LYP/6-31G(d,p), TD-DFT/BP866-31G(d,p) calculation for all model compounds.

\begin{tabular}{|c|c|c|c|c|c|c|c|}
\hline \multirow{2}{*}{ Compounds } & \multicolumn{3}{|c|}{ DFT-B3LYP/6-31G (d.p) } & \multicolumn{3}{|c|}{ DFT-BP86/6-31G (d.p) } & \multirow[b]{2}{*}{$\lambda_{\max }(\exp )$} \\
\hline & $\mathbf{E}_{\mathrm{ex}}$ & Fos $_{\text {os }}$ & $\lambda_{\max }$ & $\mathbf{E}_{\mathbf{e x}}$ & Fos $_{\text {os }}$ & $\lambda_{\max }$ & \\
\hline \multirow{3}{*}{ PCrV } & 3.71 & 0.05 & 334.14 & 3.12 & 0.04 & 397.62 & \multirow{3}{*}{$436^{9}$} \\
\hline & 4.14 & 0.44 & 300.00 & 3.52 & 0.02 & 352.49 & \\
\hline & 4.25 & 0.05 & 291.84 & 3.61 & 0.01 & 343.44 & \\
\hline \multirow{3}{*}{ PCrV-T } & 3.26 & 1.55 & 380.67 & 2.61 & 0.02 & 474.28 & \multirow{3}{*}{$466^{9}$} \\
\hline & 3.31 & 0.04 & 373.97 & 2.82 & 1.22 & 439.74 & \\
\hline & 3.88 & 0.02 & 319.30 & 3.01 & 0.01 & 411.20 & \\
\hline \multirow{3}{*}{ PCV-BiTTP } & 1.96 & 0.49 & 633.00 & 1.17 & 0.02 & 1062.34 & \multirow{3}{*}{ - } \\
\hline & 3.32 & 0.03 & 373.75 & 1.35 & 0.37 & 917.77 & \\
\hline & 3.36 & 0.31 & 369.26 & 1.85 & 0.01 & 670.04 & \\
\hline \multirow{3}{*}{ PCrV-TTN } & 2.34 & 0.58 & 529.53 & 1.27 & 0.01 & 979.37 & \multirow{3}{*}{-} \\
\hline & 3.16 & 0.01 & 391.78 & 1.44 & 0.35 & 860.84 & \\
\hline & 3.57 & 0.03 & 347.63 & 2.02 & 0.03 & 613.96 & \\
\hline \multirow{3}{*}{ PCrV-TTP } & 3.21 & 0.99 & 386.55 & 1.82 & 0.01 & 682.07 & \multirow{3}{*}{-} \\
\hline & 3.91 & 0.06 & 317.27 & 1.91 & 0.28 & 649.05 & \\
\hline & 4.09 & 0.67 & 303.03 & 2.62 & 0.06 & 473.42 & \\
\hline \multirow{3}{*}{ PCrV-PP } & 3.41 & 1.13 & 364.07 & 1.74 & 0.02 & 712.35 & \multirow{3}{*}{ - } \\
\hline & 3.63 & 0.01 & 341.23 & 1.83 & 0.22 & 675.59 & \\
\hline & 3.93 & 0.06 & 315.55 & 2.55 & 0.01 & 485.02 & \\
\hline \multirow{3}{*}{ PCrV-PT } & 3.19 & 2.21 & 388.36 & 2.21 & 1.91 & 561.02 & \multirow{3}{*}{ - } \\
\hline & 3.67 & 0.04 & 337.85 & 2.35 & 0.01 & 526.47 & \\
\hline & 3.84 & 0.16 & 323.21 & 2.45 & 0.04 & 505.13 & \\
\hline \multirow{3}{*}{ PCrV-TT } & 3.28 & 1.80 & 378.28 & 2.33 & 0.02 & 531.34 & \multirow{3}{*}{ - } \\
\hline & 3.97 & 0.06 & 312.48 & 2.41 & 1.44 & 514.55 & \\
\hline & 4.25 & 0.21 & 291.37 & 2.64 & 0.13 & 469.64 & \\
\hline
\end{tabular}

To study the optical properties, the structures by the B3LYP/6-31G(d) method were optimized. The UVvisible spectra (Fig. 12a and b) of the studied compounds were calculated using the TD-DFT method. In Tab. 4, the calculated values of maximum absorption wavelengths $\left(1_{\max }\right)$, excitation energies $\left(\mathrm{E}_{\mathrm{ex}}\right)$ and oscillator forces $\left(\mathrm{F}_{\mathrm{os}}\right)$ were presented.

Molecules with an energy gap below $3.05 \mathrm{eV}$ (PCrV-TT, PCrV-TP, PCrV-PP, PCrV-TTP, PCrVTTN, PCrV-BiTTP) have absorption maxima for both computational functions (B3LP and BP86), thus reflecting the HOMO-LUMO transition. In addition, the simulated absorption spectra (Fig. 12a and b) of all compounds studied have a shoulder, which can be attributed to the intramolecular charge transfer band caused by the $\mathrm{R}$ group introduced into the skeleton of the structures of these molecules. This indicates that these organic materials could absorb the maximum amount of incident light radiation, in particular the molecules PCrV-BiTTP, PCrV-TTN and PCrV-TTP. This property is beneficial to increase the photoelectric conversion efficiency of the solar cell containing these types of molecules.

The excitation in the S1 state corresponds exclusively to the promotion of an electron from the HOMO to the LUMO, and to the greatest oscillation force $\left(\mathrm{F}_{\mathrm{os}}<1\right)$ that comes from the $\mathrm{S} 0 \rightarrow \mathrm{S} 1$ electronic transition.

The excitation in the S1 state corresponds to $\mathrm{HOMO} \rightarrow \mathrm{LUMO}+1$, and the high values of the oscillation force $\left(\mathrm{F}_{\text {os }}>1\right)$ in these compounds comes from the $\mathrm{S} 0 \rightarrow \mathrm{S} 2$ electronic transition. 

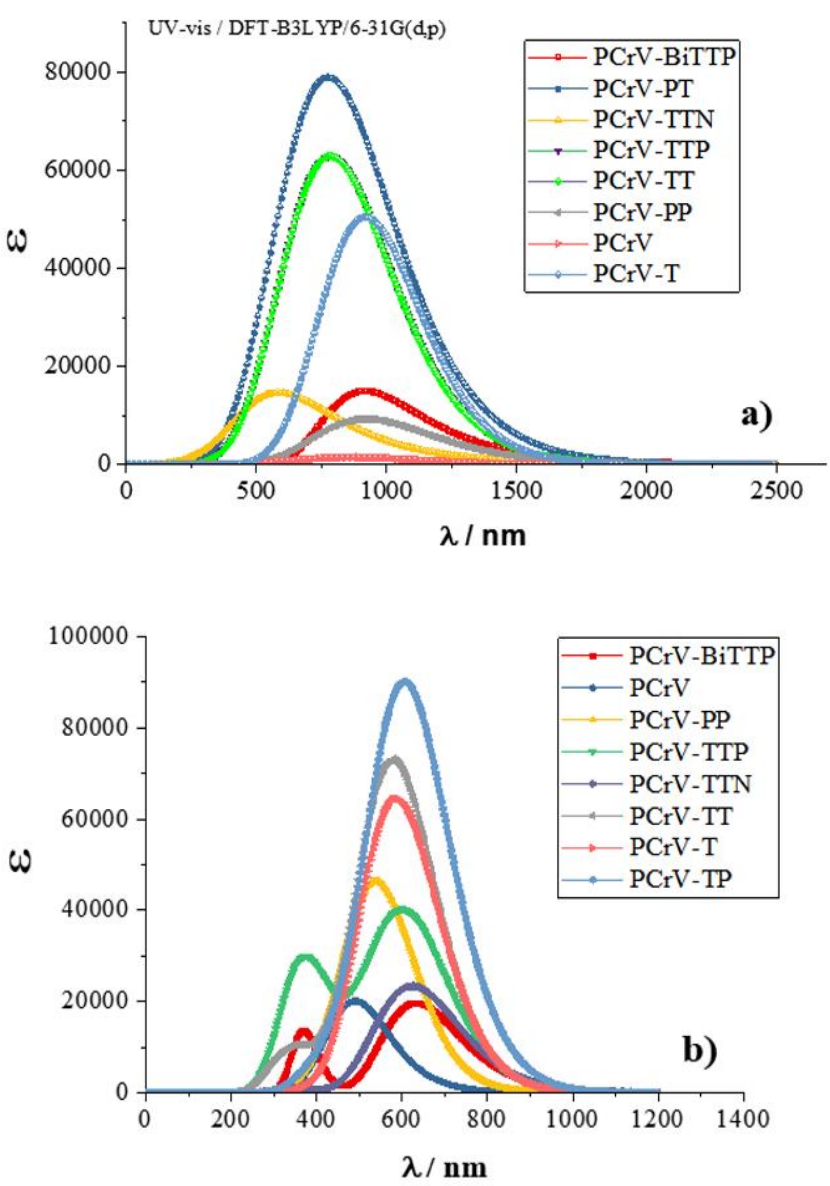

Figure 12. Data of UV-visible absorbance of all oligomers obtained at (a) DFT-BP86/6-31G (d,p) and (b) DFT-B3LYP/6-31G(d,p).
All the compounds studied show simulated wavy absorption spectra; this can be attributed to the intermolecular transfer charge in the structures of these molecules. This indicates that these organic materials could absorb the maximum of the incident light radiation. The energy range for all the structures studied is generally in the visible field.

From the absorption spectra (Fig. 12b), the electronic transitions of the double spectral band for all molecules belong to the visible field and in particular for the oligomers PCrV-BiTTP, PCrV-TTP. That is to say, the low energy radiation can excite the electrons of the system.

Concerning the energy absorption, it was found that some studied molecules absorb in the ultraviolet while others in the infrared, this factor is important for a good photovoltaic application of these molecules.

\subsection{Photovoltaics proprieties}

The theoretical values of the open circuit voltage, Voc, have been calculated from the following expression (Eq. 4 and Eq. 5) (Boussaidi et al., 2016; Bourass et al., 2017):

The energy values of LUMO (eV), HOMO $(\mathrm{eV}), \mathrm{E}$ gap $(\mathrm{eV})$ and the open circuit voltage $\mathrm{Voc}(\mathrm{eV})$ and $\alpha$ $(\mathrm{eV})$ of the studied molecules are presented in Tab. 5.

$-0.3$

$\alpha=\mid$ E LUMO (Accepteur) $|-|$ ELUMO (Donneur)

Table 5. LUMO (eV), HOMO (eV), Voc $(\mathrm{eV})$ and $\alpha$ $(\mathrm{eV})$ obtained by B3LYP/6-31 G (d,p)

\begin{tabular}{|l|c|c|c|c|}
\hline Compound & $\left|\boldsymbol{E}_{\text {номо }}\right|$ & $\left|\boldsymbol{E}_{\text {LUмо }}\right|$ & $\mathbf{V o c}(\mathbf{e V})$ & $\boldsymbol{\alpha}$ \\
\hline PCrV & 5.25 & 0.95 & 1.15 & 2.84 \\
\hline PCrV-T & 4.99 & 1.54 & 0.88 & 2.26 \\
\hline PCrV-PT & 4.63 & 1.75 & 0.53 & 2.05 \\
\hline PCrV-PP & 5.21 & 2.35 & 1.11 & 1.45 \\
\hline PCrV-TTN & 5.10 & 3.06 & 1.01 & 0.74 \\
\hline PCrV-BiTT & 5.07 & 3.33 & 0.98 & 0.47 \\
\hline Bis-PCBM & 6.10 & 3.80 & ----- & ------ \\
\hline
\end{tabular}
taking as acceptor semiconductor the Bis-PCBM within the solar cell. The molecules PCrV, PCrV-PP, PCrVTTN and PCrV-BiTT have high $\mathrm{V}_{\mathrm{OC}}$ values and low gaps, as well as small $\alpha$ values allowing the passage of electrons from the donor LUMO to the acceptor LUMO, especially for the PCrV-BiTT molecule $(\alpha=$ 0.47), with a good position of HOMO compared to that of Bis-PCBM. These arguments make these molecules good and promising candidates for photovoltaic applications. 


\section{Conclusions}

In this paper, quantum chemical studies on the geometry and electronic properties of several compounds based on 2.7-divnyl-carbazol are carried out to show the variation effects of alkyl $\mathrm{R}$ groups.

The approach of increasing the conjugation length in the skeleton of these oligomers offers good optoelectronic and photovoltaic properties for the studied systems. This is clearly justified by the results obtained which show low bandgap values especially for the molecules PCrV-BiTTP, PCrV-TTP and PCrVTTN. Add to this the high values of the absorption maxima $\lambda_{\max }$ as well as the good location of the HOMO and LUMO levels of these molecules. These results lead to suggest these materials as good candidates for applications in organic solar cells.

Two functionalities were used to describe the geometrical and optoelectronic properties to compare the results, and the BP86 function was found to give good results at the energy gap level, while other parameters using the B3LYP function give the best results.

\section{Authors' contribution}

Conceptualization: Jabha, M.; Elalaoui, A.

Data curation: Jabha, $M$.

Formal Analysis: Jabha, M.

Funding acquisition: Not applicable

Investigation: Jabha, M.; Mabrouk. E. H.

Methodology: Jabha, M.; Elalaoui, A.; Jarid, A.

Project administration: Elalaoui, A.

Resources: Not applicable

Software: Not applicable

Supervision: Elalaoui, A.; Jarid, A.

Validation: Elalaoui, A.; Mabrouk. E. H.

Visualization: Elalaoui, A.; Jarid, A.

Writing - original draft: Jabha, M.

Writing - review \& editing: Jabha, M.; Mabrouk. E. H.

\section{Data availability statement}

All data sets were generated and analyzed in the current study.

\section{Funding}

Not applicable

\section{Acknowledgments}

The authors are grateful to the "Association Marocaine des Chimistes Théoriciens" (AMCT) for its pertinent help concerning the programs.

\section{References}

Ayers, P. W. The physical basis of the hard/soft acid/base principle. Faraday Discuss. 2007, 135, 161-190. https://doi.org/10.1039/B606877D

Baek, M.-J.; Lee, S.-H.; Kim, D. H.; Lee, Y.-S. Carbazolethieno[3,4-b]thiophene polymers: Synthesis and photovoltaic applications. Macromol. Res. 2012, 20 (2), 147-154. https://doi.org/10.1007/s13233-012-0019-0

Baseden, K. A.; Tye, J. W. Introduction to Density Functional Theory: Calculations by Hand on the Helium Atom. J. Chem. Educ. 2014, 91 (12), 2116-2123. https://doi.org/10.1021/ed5004788

Becke, A. D. Density-functional exchange-energy approximation with correct asymptotic behavior. Phys. Rev. A. 1988, $38 \quad$ (6), 3098-3100. https://doi.org/10.1103/PhysRevA.38.3098

Blouin, N.; Michaud, A.; Gendron, D.; Wakim, S.; Blair, E.; Neagu-Plesu, R.; Belletête, M.; Durocher, G.; Tao, Y.; Leclerc, M. Toward a Rational Design of Poly(2,7Carbazole) Derivatives for Solar Cells. J. Am. Chem. Soc. 2008, 130 (2), 732-742. https://doi.org/10.1021/ja0771989

Bourass M.; Benjelloun, A. T.; Benzakour, M.; Mcharfi, M.; Jhilal, F.; Serein-Spirau, F.; Sotiropoulos, J. M.; Bouachrine, M. DFT/TD-DFT characterization of conjugational electronic structures and spectral properties of materials based on thieno[3,2-b][1]benzothiophene for organic photovoltaic and solar cell applications. J. Saudi Chem. Soc. 2017, $21 \quad$ (5), 563-574. https://doi.org/10.1016/j.jscs.2017.01.001

Boussaidi, S., Alaoui, Y., Abderrahim, E., Fitri, A., Benjelloun, A. T., Hsaine, Z., Chaib, H., Bouachrine, M., Hamidi, M., Hadda, T. B., Theoretical study of the effect of substitution with alternating donor and acceptor groups on the optoelectronic and photovoltaic properties of some oligomers containing thiophene and phenylene. Arab. J. Chem. Environ. Res. 2016, 3 (1), 51-63.

Cai, Z.-L.; Sendt, K.; Reimers, J. R. Failure of densityfunctional theory and time-dependent density-functional theory for large extended $\pi$ systems. J. Chem. Phys. 2002, 117 (12), 5543-5549. https://doi.org/10.1063/1.1501131

Chen, Q.; Zhou, H.; Hong, Z.; Luo, S.; Duan, H.-S.; Wang, H.-H.; Liu, Y.; Li, G.; Yang, Y. Planar Heterojunction Perovskite Solar Cells via Vapor-Assisted Solution Process. 
J. Am. Chem. Soc. 2014, 136 (2), 622-625. https://doi.org/10.1021/ja411509g

Cherkasov, A. R.; Galkin, V. I.; Zueva, E. M.; Cherkasov, R. A. The concept of electronegativity. The current state of the problem. Russ. Chem. Rev. 1998, 67 (5), 375-392. https://doi.org/10.1070/RC1998v067n05ABEH000383

Cramer, C. J.; Truhlar, D. G. Density functional theory for transition metals and transition metal chemistry. Phys. Chem. Chem. Phys. 2009, 11 (46), 10757-10816. https://doi.org/10.1039/B907148B

Davidson, C. L.; De Gee, A. J.; Feilzer, A. The Competition between the Composite-Dentin Bond Strength and the Polymerization Contraction Stress. J. Dent. Res. 1984, 63 (12), 1396-1399.

https://doi.org/10.1177/00220345840630121101

Francl, M. M.; Pietro, W. J.; Hehrea, W. J.; Binkley, J. S.; Gordon, M. S.; DeFrees, D. J.; Pople, J. A. Self-consistent molecular orbital methods. XXIII. A polarization-type basis set for second-row elements. J. Chem. Phys. 1982, 77 (7), 3654-3665. https://doi.org/10.1063/1.444267

Fukuta, S.; Wang, Z.; Miyane, S.; Koganezawa, T.; Sano, T.; Kido, J.; Mori, H.; Ueda, M.; Higashihara, T. Synthesis of 1,3,4-thiadiazole-based donor-acceptor alternating copolymers for polymer solar cells with high open-circuit voltage. Polym. J. 2015, 47 (7), 513-521. https://doi.org/10.1038/pj.2015.19

Ganji, M. D.; Tajbakhsh, M.; Kariminasab, M.; Alinezhad, H. Tuning the LUMO level of organic photovoltaic solar cells by conjugately fusing graphene flake: A DFT-B3LYP study. Phys. E: Low-Dimens. Syst. Nanostructures. 2016, 81, 108-115. https://doi.org/10.1016/j.physe.2016.03.008

Garrity, K. F.; Bennett, J. W.; Rabe, K. M.; Vanderbilt, D. Pseudopotentials for high-throughput DFT calculations. Comput. Mater. Sci. 2014, 81, 446-452. https://doi.org/10.1016/j.commatsci.2013.08.053

Gaussian 09; Gaussian, Inc.: Wallingford, 2009. https://gaussian.com/glossary/g09/ (accessed 2017-12-16).

Gill, P. M. W.; Johnson, B. G.; Pople, J. A.; Frisch, M. J. The performance of the Becke-Lee-Yang-Parr (BLYP) density functional theory with various basis sets. Chem. Phys. Lett. 1992, 197 (4-5), 499-505. https://doi.org/10.1016/0009-2614(92)85807-M

Huang, F. High-performance polymer solar cells with $>10 \%$ efficiency. Sci. China Chem. 2015, 58 (2), 190. https://doi.org/10.1007/s11426-014-5314-5

Jabha, M.; Abdellah, A. Study Optoelectronic and Geometric Properties of New compounds Based on Carbazolethiophene Bridged for Solar Cells. Orbital: Electron. J.
Chem. 2018, $10 \quad$ (7),

https://doi.org/10.17807/orbital.v10i7.1322

$552-560$

Jacquemin, D.; Wathelet, V.; Perpète, E. A.; Adamo, C. Extensive TD-DFT Benchmark: Singlet-Excited States of Organic Molecules. J. Chem. Theory Comput. 2009, 5 (9), 2420-2435. https://doi.org/10.1021/ct900298e

Kato, S.-I.; Shimizu, S.; Kobayashi, A.; Yoshihara, T.; Tobita, S.; Nakamura, Y. Systematic Structure-Property Investigations on a Series of Alternating CarbazoleThiophene Oligomers. J. Org. Chem. 2014, 79 (2), 618-629. https://doi.org/10.1021/jo402416f

Kato, S.-I.; Yamada, Y.; Hiyoshi, H.; Umezu, K.; Nakamura, Y. Series of Carbazole-Pyrimidine Conjugates: Syntheses and Electronic, Photophysical, and Electrochemical Properties. J. Org. Chem. 2015, 80 (18), 9076-9090. https://doi.org/10.1021/acs.joc.5b01409

Khalid, M.; Ali, A.; Rehman, M. F. U.; Mustaqeem, M.; Ali, S.; Khan, M. U.; Asim, S.; Ahmad, N.; Saleem, M. Exploration of Noncovalent Interactions, Chemical Reactivity, and Nonlinear Optical Properties of Piperidone Derivatives: A Concise Theoretical Approach. ACS Omega, 2020, 5 (22), 13236-13249. https://doi.org/10.1021/acsomega.0c01273

Kim, Y.; Cho, H.-H.; Kim, T.; Liao, K.; Kim, B. J. Terpolymer approach for controlling the crystalline behavior of naphthalene diimide-based polymer acceptors and enhancing the performance of all-polymer solar cells. Polym. J. 2016, 48 (4), 517-524. https://doi.org/10.1038/pj.2016.22

Koh, S. E.; Risko, C.; Silva Filho, D. A. da; Kwon, O.; Facchetti, A.; Brédas, J.-L.; Marks, T. J.; Ratner, M. A. Modeling Electron and Hole Transport in FluoroareneOligothiopene Semiconductors: Investigation of Geometric and Electronic Structure Properties. Adv. Funct. Mater. 2008, $18 \quad$ (2), 332-340. https://doi.org/10.1002/adfm.200700713

Laurent, A. D.; Jacquemin, D. TD-DFT benchmarks: A review. Int. J. Quantum Chem. 2013, 113 (17), 2019-2039. https://doi.org/10.1002/qua.24438

Leclerc, N.; Michaud, A.; Sirois, K.; Morin, J.-F.; Leclerc, M. Synthesis of 2,7-Carbazolenevinylene-Based Copolymers and Characterization of Their Photovoltaic Properties. Adv. Funct. Mater. 2006, $16 \quad$ (13), 1694-1704. https://doi.org/10.1002/adfm.200600171

Leliège, A; Grolleau, J.; Allain, M.; Blanchard, P.; Demeter, D; Rousseau, T.; Roncali, J. Small D- $\pi-A$ Systems with oPhenylene-Bridged Accepting Units as Active Materials for Organic Photovoltaics. Chem. Eur. J. 2013, 19 (30), 99489960. https://doi.org/10.1002/chem.201301054 
Miranda-Quintana, R. A.; González, M. M.; Ayers, P. W. Electronegativity and Redox Reactions. Phys. Chem. Chem. Phys. 2016, 18 (32), 22235-22243. https://doi.org/10.1039/C6CP03213C

Mitin, A. V.; Baker, J.; Pulay, P. An improved 6-31G* basis set for first-row transition metals. J. Chem. Phys. 2003, 118 (17), 7775-7783. https://doi.org/10.1063/1.1563619

Nazim, M.; Ameen, S.; Seo, H.-K.; Shin, H. S. Effective DA-D type chromophore of fumaronitrile-core and terminal alkylated bithiophene for solution-processed small molecule organic solar cells. Sci. Rep. 2015, 5 (1), 1-10. https://doi.org/10.1038/srep11143

Nishiyama, J.; Ellison, E. C.; Mizuno, G. R.; Chipault, J. R. Micro-determinations of $\alpha$-tocopherol in tissue lipids. $J$. Nutr. Sci. Vitaminol. 1975, 21 (5), 355-361. https://doi.org/10.3177/jnsv.21.355

Parr, R. G.; Pearson, R. G. Absolute hardness: companion parameter to absolute electronegativity. J. Am. Chem. Soc. 1983, $105 \quad$ (26), https://doi.org/10.1021/ja00364a005

Scharber, M. C.; Sariciftci, N. S. Efficiency of bulkheterojunction organic solar cells. Prog. Polym. Sci. 2013, 38 (12), 1929-1940. https://doi.org/10.1016/j.progpolymsci.2013.05.001

Tarascon, J.-M. Le photovoltaïque: principes et filières inorganiques, organiques, hybrids. Chaire Développement durable, 2011, p. 56.

Toub, D. A Review of Photovoltaic Cells, Department of electrical and Computer engineering, University of Rochester, Rochester, New York, (2007) 1-3. http://www2.ece.rochester.edu/courses/ECE423/ECE223_42 3_MSC426\%20Workshop06/term\%20papers\%2006/Toub_0 6.pdf (accessed 2019-11-26).

$\mathrm{Xu}, \mathrm{X}$; Goddard, W. A. The X3LYP extended density functional for accurate descriptions of nonbond interactions, spin states, and thermochemical properties. Proc. Natl. Acad. Sci. U.S.A. 2004, $101 \quad$ (9), 2673-2677. https://doi.org/10.1073/pnas.0308730100

Zeyada, H. M.; EL-Nahass, M. M.; El-Shabaan, M. M. Photovoltaic properties of the 4H-pyrano[3,2-c]quinoline derivatives and their applications in organic-inorganic photodiode fabrication. Synth. Met. 2016, 220, 102-113. https://doi.org/10.1016/j.synthmet.2016.05.028

Zhao, W.; Cai, W.; Xu, R.; Yang, W.; Gong, X.; Wu, H.; Cao, Y. Novel conjugated alternating copolymer based on 2,7-carbazole and 2,1,3-benzoselenadiazole. Polymer. 2010, $51 \quad$ (14), 3196-3202. https://doi.org/10.1016/j.polymer.2010.04.057
Zhou, Z.; Parr, R. G. New measures of aromaticity: absolute hardness and relative hardness. J. Am. Chem. Soc. 1989, 111 (19), 7371-7379. https://doi.org/10.1021/ja00201a014 